УДК: 377.031

\title{
СОЗДАНИЕ ЛИНГВО-ИНФОРМАЦИОННОЙ ОБРАЗОВАТЕЛЬНОЙ СРЕДЫ В ВУЗАХ С ПОМОЩЬЮ ПРОФЕССИОНАЛЬНОГО ГЛОССАРИЯ НА АНГЛИЙСКОМ ЯЗЫКЕ
}

\author{
Дёрина Наталья Владимировна \\ к.ф.н., доцент \\ Дёрина Ксения Сергеевна \\ Магнитогорский государственный \\ Технический университет им. Г.И.Носова
}

Аннотация: В работе рассмотрены виды и классификация глоссариев, определено место профессионального глоссария в лингво-информационной образовательной среды. Определены основные правила компоновки профессиональных глоссариев и структура такого глоссария. Проведен теоретико-множественный анализ исследуемой области. Определены основные компоненты модели, выявлена их структура и определены все возможные взаимодействия между ними.

Авторами рассматривается такой инструмент как профессиональный глоссарий в качестве фактора создания лингво-информационной образовательной среды. C функциональной точки зрения в глоссариях реализуется междисциплинарная функция языка, то есть, использование языка с целью обсуждения тематик по разным специализациям при помощи самого языка, а не внешнего мира.

Профессиональные глоссарии входят в состав комплекса образовательных ресурсов. Применение профессиональных глоссариев при формировании лингво-информационной образовательной среды позволяет: повысить эффективность усвоения языковой и предметной информации обучающимися; расширить лексический запас обучающихся; отобрать, 
адаптировать и сформировать базу релевантных терминов для будущего использования их обучающимися в учебной и профессиональной деятельности.

Ключевые

слова:

профессиональный

глоссарий,

лингво-информационная образовательная среда, терминология информатики и вычислительной техники на английском языке

\title{
CREATING A LANGUAGE-INFORMED EDUCATIONAL ENVIRONMENT IN ENGLISH WITH A PROFESSIONAL GLOSSARY
}

\section{Dyorina Natalya Vladimirovna \\ Dyorina Xenia Sergeevna}

\begin{abstract}
This paper presents the types and classification of glossaries, defines the place of a professional glossary within the linguistic-informational educational environment. The main rules for the layout of professional glossaries and the structure of such a glossary are defined.

The author considers such a tool as a professional glossary as a factor for the creation of a linguistic-informative educational environment. From a functional point of view, glossaries realize the interdisciplinary function of language, that is, the use of language in order to discuss topics in different specializations by means of the language itself, rather than the outside world.

Professional glossaries are part of a set of educational resources. The application of professional glossaries in the formation of a linguistic-informational educational environment allows increasing the efficiency of language and subject information assimilation by students; expanding the vocabulary of students; selecting, adapting and forming the base of relevant terms for their future use by students in educational and professional activities.
\end{abstract}

Key words: professional glossary, linguistic-information educational environment, computer science and computer technology terminology in English 
Понятие «лингво-информационная образовательная среда» не получило широкого анализа на сегодняшний день в научной литературе, но специалисты дают описание информационной образовательной среде как дидактическому, психолого-педагогическому, коммуникативному, материально-техническому обеспечению образовательного процесса. Данное обеспечение включает средства обучения, основанные на новых коммуникационных и информационных технологиях, учебную и научную информацию, способствующую формированию профессионально значимых и социально важных качеств личности будущего специалиста - информацию двоякого рода: как входящую в официально предписанную и зафиксированную в виде учебных программ, так и дополнительную информацию учебного характера [1, с. 102].

Лингво-информационная образовательная среда создается при обучении английскому языку, при освоении навыков профессиональной иноязычной речи посредством информационных технологий, направленных на эффективное усвоение учебного материала [2, c. 16]. Что касается структуры, лингво-информационная образовательная среда может быть представлена в виде модели - комплекса компонентов, характерных для композиции информационной образовательной среды, но подразумевая при этом обучение английскому языку в рамках профессионально-ориентированного образования: интерактивное ядро - блок взаимодействия (участники образовательного процесса); формирующее ядро - блок организационный (средства мотивации, организации и управления); информационно-образовательный блок (телекоммуникационные средства, обучающие программные средства, периодические электронные издания вуза, обучающие ресурсы вуза, банки и базы знаний) [3, с. 429].

Изначально термин «глоссарий» использовался применительно к толковым словарям устаревших слов - глоссе. Согласно энциклопедическому

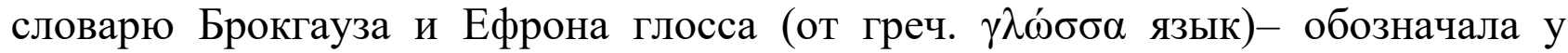
греков и римлян непонятные или устаревшие слова, толкованиями которых грамматисты занимались при изучении поэзии Гомера [4]. 
В различных областях знаний глоссарии могут представлять отдельное исследование, представляющее собой список терминов [5, с. 12], требующих описательных комментариев и пояснений [6].

Современный энциклопедический словарь дает следующее определение глоссария - собрание глосс - непонятных слов или выражений - с толкованием (толковый глоссарий) или переводом на другой язык (переводческий глоссарий) [7]. Глоссарием также можно называть список часто используемых выражений [8].

Анализ существующих источников позволил выделить следующие виды глоссариев:

1. переводческий;

2. тематический;

3. технический;

4. научный;

5. специализированный.

Рассмотрим каждый из видов подробнее.

Переводческий глоссарий представляет собой список терминов, относящихся к определенному тексту, с соответствующим переводом, согласованным с клиентом или внутри компании [9, с. 225].

В тематическом глоссарии в основе классификации лежат сферы и тематика общения. Источник отбора терминов - речевой материал: тематические высказывания и тексты. Из них выбираются тематические термины на основе их функционирования в рамках определенной темы и смысловой связи с ней. При этом смысловая связь с темой мыслится и на уровне лексического значения слов, и на уровне соотнесенности данной лексической единицы с той или иной темой.

Технический глоссарий составляется с использованием открытых нормативных правовых актов и нормативно-технических документов, наиболее часто используемых в тех или иных технических, научно-исследовательских и опытно-конструкторских областях. 
В научном глоссарии приведены точные измеряемые величины, научная формулировка и точное изложение научных принципов.

Специализированный глоссарий - это глоссарий очень узкой направленности, который предназначен для специалистов определенного профиля. Он обязательно должен содержать в себе толкование значения термина, подробный комментарий к нему [10]. Если такой глоссарий является переводческим, то он непременно будет содержать перевод с языка оригинала с примером употребления.

Таким образом, терминологический глоссарий - это единый комплекс информации в соответствии с исследовательской или практической задачей.

Далее необходимо определить место глоссариев в лингво-информационной образовательной среде, поскольку профессиональный глоссарий выступает одним из основных факторов построения лингво-информационной образовательной среды в высшей школе. Лингво-информационная образовательная среда представляет собой систему, состоящую из пяти модулей (рис. 1):

1. программно-телекоммуникационный модуль;

2. педагогический модуль;

3. комплекс образовательных ресурсов;

4. организационное пространство;

5. обучающиеся.

Эти модули объединены в блоки: интерактивное ядро - блок взаимодействия (педагогический модуль, обучающиеся); формирующее ядро организационного блока пространство); информационно-образовательный блок (программно-телекоммуникационный модуль, комплекс образовательных ресурсов). 


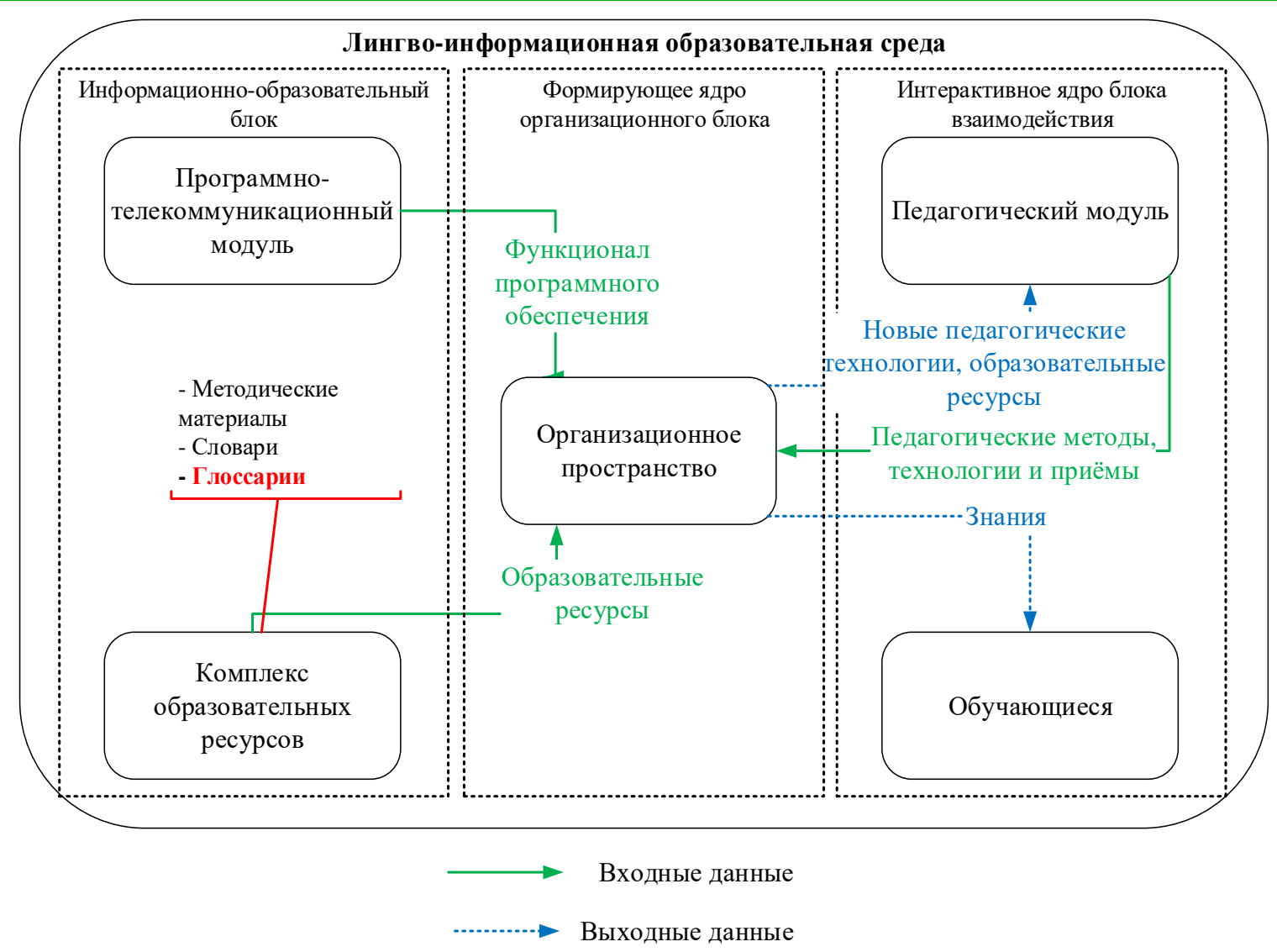

Рис. 1. Место глоссариев в лингво-информационной образовательной среде

Программно-телекоммуникационный модуль состоит из набора программного обеспечения, предоставляющий необходимый функционал для эффективной обработки и дальнейшего применения образовательных ресурсов.

Педагогический модуль - педагогический состав, владеющий педагогическими методами, технологиями и приёмами, необходимыми для эффективного усвоения языковой и предметной информации, а также для формирования компетенций по эффективному применению английского языка в профессиональной деятельности. К тому же педагогический модуль выполняет разработку новых и доработку существующих педагогических методов, технологий и приёмов с появлением иных образовательных ресурсов.

Комплекс образовательных ресурсов - набор учебников, учебных пособий, учебно-методических пособий, словарей, глоссариев, компьютерных тренажеров. 
Информационно-образовательное пространство интегрирует в себе всю информацию на традиционных и электронных носителях, программно-телекоммуникационные технологии взаимодействия и педагогические методы, из которого обучающиеся получают весь необходимый набор знаний.

Обучающиеся - субъекты образовательного процесса - студенты вузов.

Рассмотрев в предыдущем параграфе виды глоссариев, и определив, что терминологические глоссарии входят в состав комплекса образовательных ресурсов, можно сделать вывод о том, что в рамках лингво-информационной образовательной среды используются профессиональные глоссарии.

Применение профессиональных глоссариев при формировании лингво-информационной образовательной среды позволяет:

1) повысить эффективность усвоения языковой и предметной информации обучающимися;

2) расширить лексический запас обучающихся;

3) отобрать, адаптировать и сформировать базу релевантных терминов для будущего использования их обучающимися в учебной и профессиональной деятельности.

Исходя из специфики какой-либо профессиональной деятельности, возникает необходимость компоновки таких глоссариев, где будут отсутствовать существенно различающиеся переводы и толкования терминов. В некоторых случаях особенно важно использовать конкретное значение термина и не допускать каких-либо вариаций.

Профессиональный глоссарий позволяет свести к минимуму неточности при переводе специализированной терминологии. Составление такого глоссария помогает обучающимся работать с узкоспециализированными терминами и правильно употреблять их. Для определения требований к созданию профессиональных глоссариев необходимо рассмотреть структуру глоссария в целом. 
В общем случае статья глоссария - это определение термина. Она состоит из двух частей:

1) точная формулировка термина в именительном падеже;

2) содержательная часть, со всей полнотой раскрывающая смысл и суть данного термина [11, с. 57].

При этом необходимо соблюдать правила компоновки глоссария:

- отобранные термины и понятия должны относиться к определенной тематике;

- обязательно указывается ссылка на источник;

- термины располагаются в алфавитном порядке или в порядке употребления в процессе чтения.

Принимая во внимание то, что в работе рассматривается профессиональный глоссарий, структура статьи такого глоссария может быть представлена следующими компонентами:

1) точная формулировка термина в именительном падеже на языке оригинала;

2) указание части речи термина;

3) точный перевод или варианты перевода термина в именительном падеже;

4) содержательная часть, со всей полнотой раскрывающая смысл и суть данного термина на языке перевода;

5) контекст употребления термина.

Отсюда следует вывод о том, что правила для компоновки профессиональных глоссариев остаются такими же, как и для обычных глоссариев.

Используя выработанные правила компоновки глоссария и структуру статьи глоссария, была разработана модель профессионального глоссария (рис. 2). 


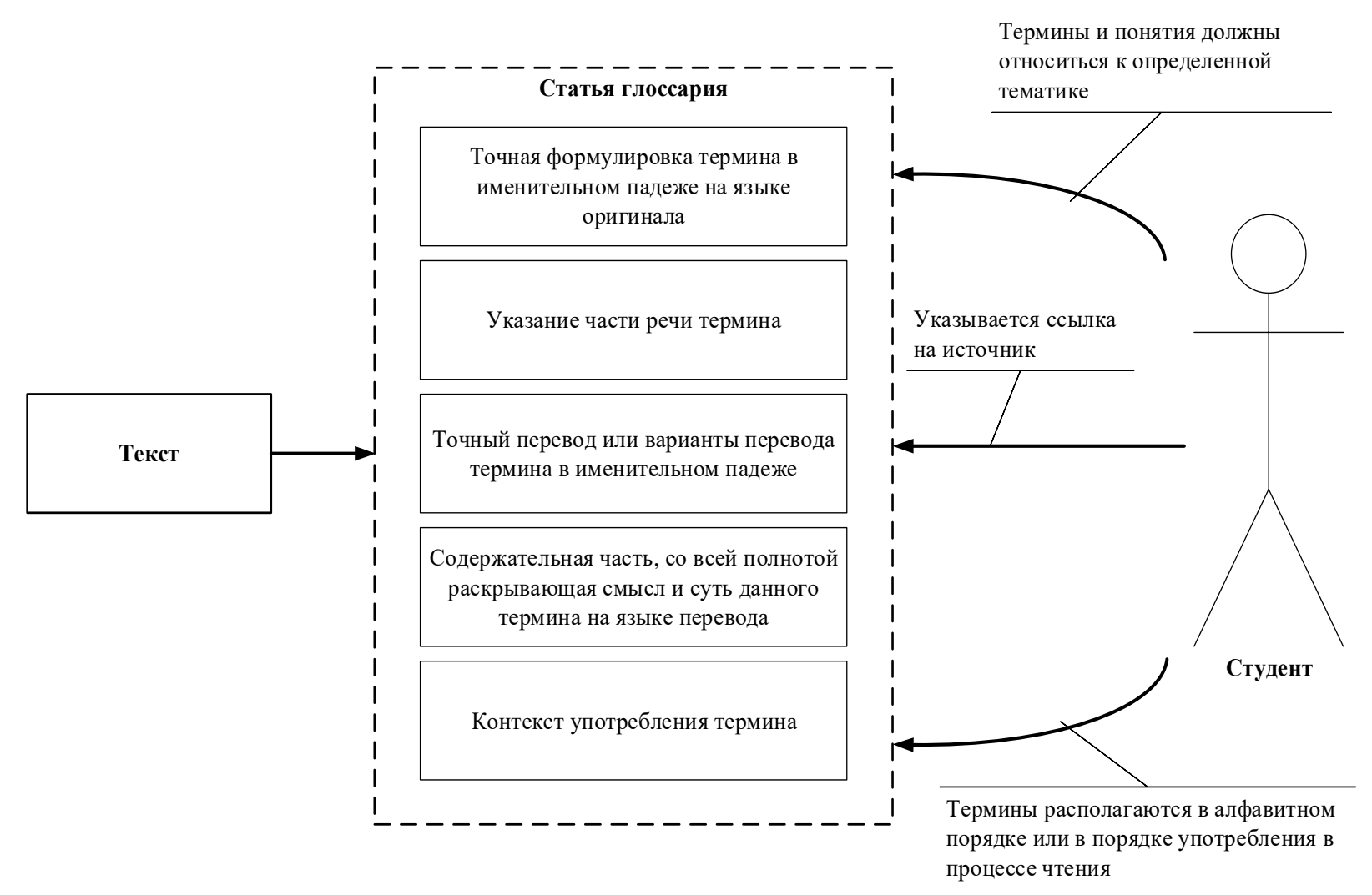

Рис. 2. Модель профессионального глоссария

Руководствуясь правилами отбора терминов и зная структуру статьи профессионального глоссария, студент высшей школы сможет составить такой глоссарий.

В ходе изучения научных источников по теме исследования выделен ряд проблем составления профессионального глоссария. Зарицкая Л.А. в работе [12, с. 203] отмечает две проблемы:

- стандартизация и унификация терминологии по направлениям обучения;

- способ предоставления многозначных и омонимичных терминов.

Помимо этого, ученые отмечают проблему выделения критериев для отбора терминов. Наиболее подробное описание критериев отбора лексики встречается в работе [13, с. 100] А.Г. Рудаковой. Исследователь выделяет три группы критериев:

- статистические;

- тематические; 
- лексические.

Основными критериями отбора статистической группы являются критерий частотности и критерий распространенности. Под частотностью следует понимать суммарное количество употреблений данного слова в отдельном источнике или совокупности источников. Под распространенностью подразумевается количество источников, в которых данное слово встретилось хотя бы раз.

В группу тематических критериев входят тематический критерий, представляющий собой способ определения важности слова в зависимости от того, в какой мере это может быть полезным и необходимым в данном жанре учебной тематики; критерий, определяющий способности слова, позволяющий считать наиболее важными те слова, с помощью которых можно описать вещи и понятия данного тематического жанра и, наконец, семантический критерий, заключающийся в том, что при отборе предпочтение отдается словам, выражающим наиболее важные понятия по данной тематике [14, с. 571].

К лексическим критериями можно отнести:

1) критерий сочетаемости, по которому ценность слова зависит от его способности сочетаться с другими словами и создавать наибольшее количество словосочетаний;

2) критерий словообразовательной изенности, отдающий предпочтение так называемым базовым словам. Эти слова обладают способностью образовывать производные слова. Максимальное количество производных основ свидетельствует о максимальной деривационной потенции конкретного базового слова;

3) критерий многозначности слова, по которому выше оцениваются слова с развитой системой значений, поскольку, чем больше у слова значений, тем больше возможностей оперировать им и тем полезнее его знать;

4) критерий стилистической ограниченности, который обеспечивает нейтральность отбираемых единиц в стилистическом плане; 
5) критерий образцовости слова, рекомендующий включать в лексический минимум те слова, которые иллюстрируют основные словообразовательные модели и образцы их семантизации;

6) критерий строевой способности, согласно которому в лексический минимум должны быть включены строевые слова, играющие ведущую роль в понимании незнакомого иностранного текста и обладающие конструктивными функциями.

При теоретико-множественном анализе определяются: анализ разработок для создания профессионального глоссария и исследование глоссария как средства формирования лингво-информационной образовательной среды.

Прежде всего, необходимо провести анализ существующих средств создания профессиональных глоссариев, выявить их сильные и слабые стороны и на их основе сформулировать требования к модели процесса составления профессионального глоссария и критерии отбора терминов. Затем необходимо определить состав компонентов и их функционал, которые необходимы для создания модели процесса составления профессионального глоссария. Зная набор компонентов, необходимо проанализировать способы получения от них данных, с целью их дальнейшего использования в создаваемой лингво-информационной модели процесса составления профессионального глоссария.

Используя полученные в ходе теоретико-множественного анализа данные, формируется структура данных, отражающая всю имеющуюся для модели процесса составления профессионального глоссария информацию и зависимости в ней. Затем можно приступать к разработкам алгоритмов и методов составления профессионального глоссария.

Таким образом, можно построить новую модель процесса составления профессионального глоссария, учитывая достоинства существующей, и дополняя ее новыми особенностями.

Исходные данные в исследовании можно разбить на 2 группы: критерии отбора терминов и лексические данные (рис. 3). 
Под критериями отбора, следует понимать измерительный признак или показатель, на основе которого производят оценку отбираемых слов. Лексические данные включают в себя термины, которые вводит пользователь самостоятельно. Также возможно использование анализатора текста с загруженным ранее документом, из которого в соответствии с выдвинутыми критериями отбираются термины в глоссарий.

Модель процесса составления профессионального глоссария предназначена для обеспечения эффективной компоновки профессиональных глоссариев, на основе анализа текстовых источников.

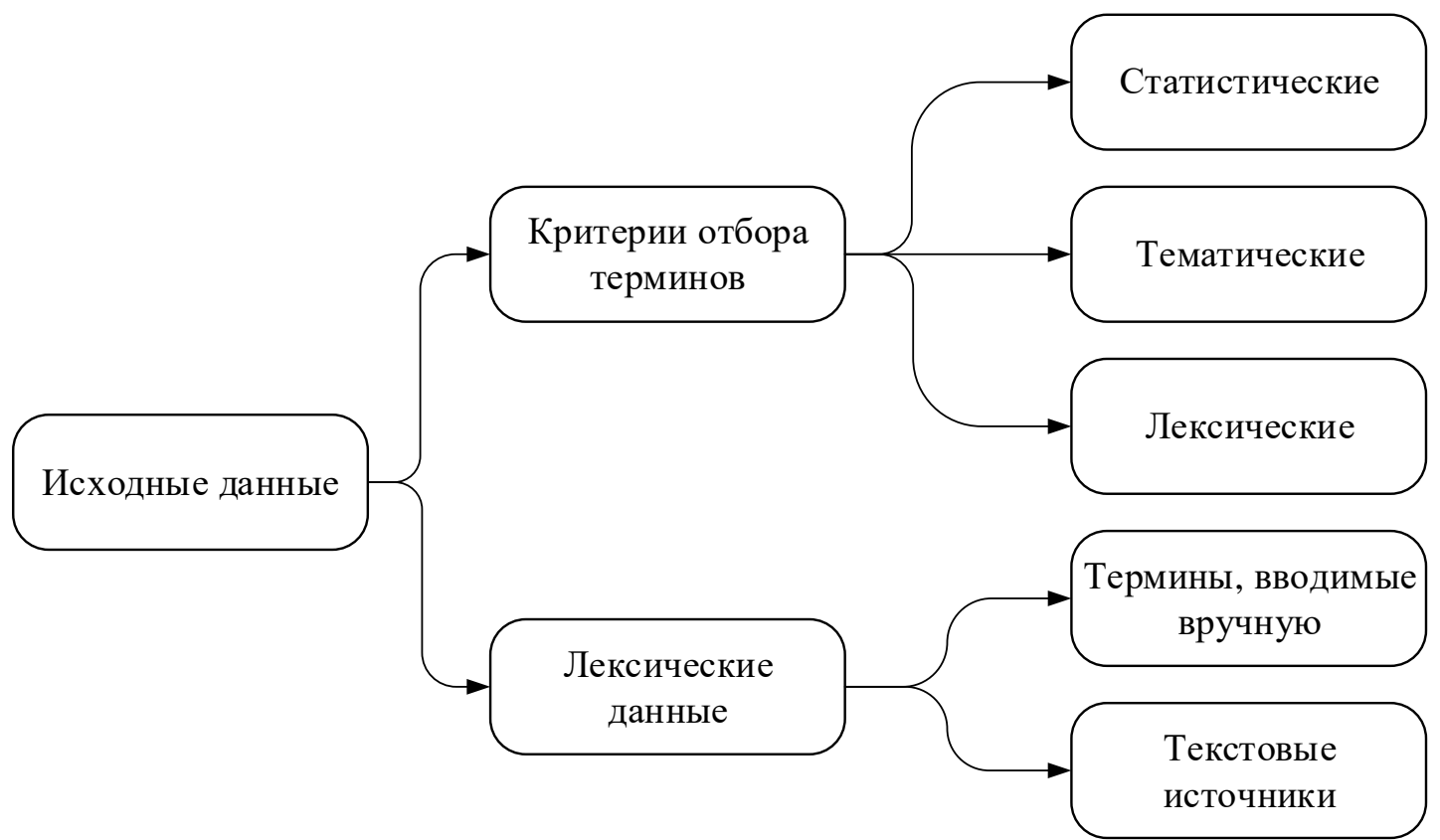

Рис. 3. Ментальная карта исходных данных

В ходе теоретико-множественного анализа определен состав компонентов модели процесса составления профессионального глоссария:

- компонент «Анализ текста»;

- компонент «Хранилище данных»;

- компонент «Редактор глоссария».

Прежде всего, текстовая информация загружается в компонент «Анализ текста», которая позволяет ее проанализировать и на основании критериев 
сформировать профессиональный глоссарий. Далее глоссарий попадает в компонент «Хранилище данных», где он будет храниться до последующих действий пользователя. Наконец, «Редактор глоссария» предназначен для пользовательского редактирования, добавления или удаления терминов из глоссария.

Визуализация модели процесса составления профессионального глоссария выполнена на рисунке 4.

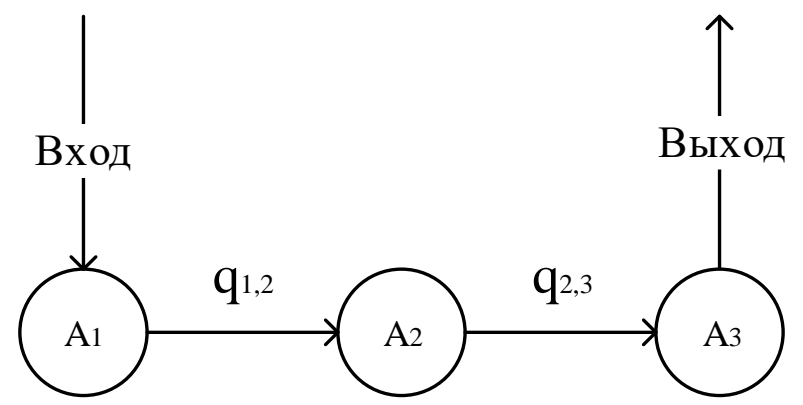

Рис. 4. Взаимодействие компонентов модели процесса составления профессионального глоссария

Описание объектов, используемых на рисунке 4 и входящих в модель процесса составления профессионального глоссария, приведено в таблице 1. В таблице 2 приведено описание управляющих взаимосвязей между объектами.

Таблица 1

Описание элементов объектно-множественной модели процесса составления профессионального глоссария

\begin{tabular}{|c|c|}
\hline Название элемента & Описание \\
\hline $\mathrm{A}_{1}$ & Информационное обеспечение \\
\hline $\mathrm{A}_{2}$ & Математическое обеспечение \\
\hline $\mathrm{A}_{3}$ & Программное обеспечение \\
\hline
\end{tabular}


Таблица 2

Описание управляющих взаимосвязей между объектами модели процесса составления профессионального глоссария

\begin{tabular}{|c|c|c|}
\hline $\begin{array}{c}\text { Название } \\
\text { потока }\end{array}$ & Вид потока & Описание потока \\
\hline $\mathrm{q}_{1,2}$ & Информационный & Передача текста в анализатор \\
\hline $\mathrm{q}_{2,3}$ & Информационный & Выгрузка данных в хранилище \\
& & глоссариев \\
\hline
\end{tabular}

Рассмотрим более подробно каждое из них. Информационное обеспечение включает в себя тексты, для которых необходимо сформировать профессиональный глоссарий, а также термины, вводимые вручную. Программное обеспечение включает в себя компонент анализа текста, редактирования полученных данных, а также систему хранения готовых глоссариев. Математическое обеспечение включает в себя критерии отбора терминов в профессиональные глоссарии. Полное представление модели процесса составления профессионального глоссария планирования представлено на рисунке 5.

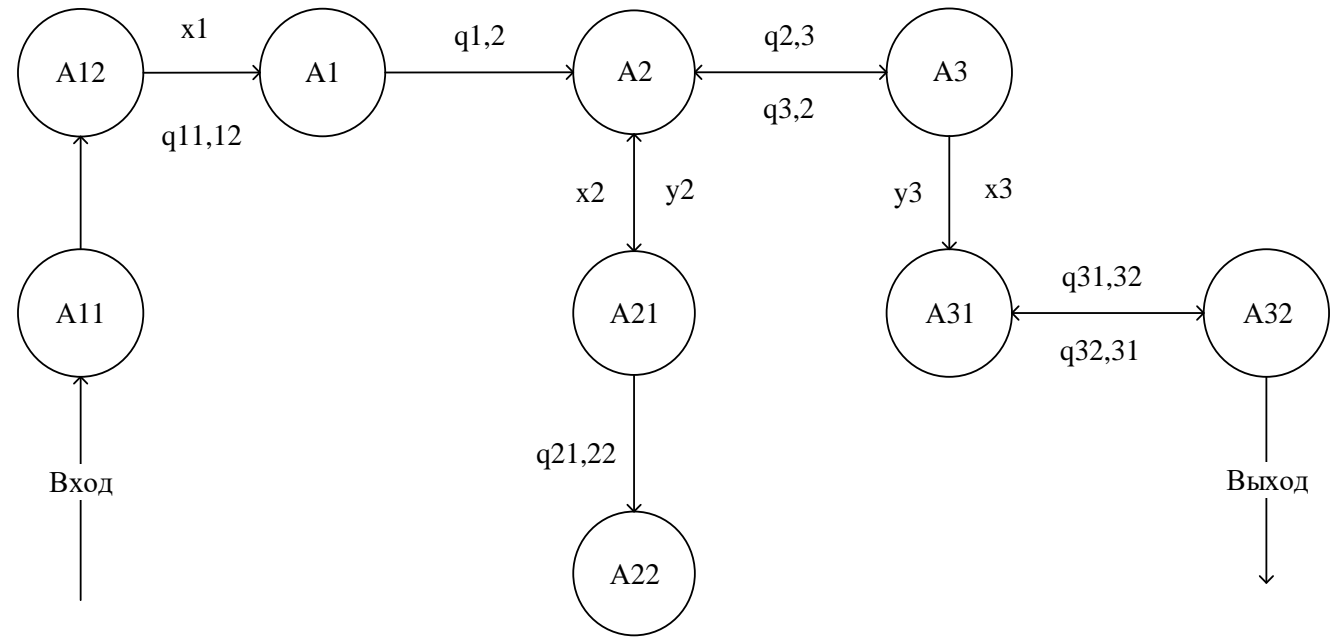

Рис. 5. Взаимодействие компонентов процесса составления профессионального глоссария 
Описание объектов, используемых на рисунке 5 и входящих в модели процесса составления профессионального глоссария, приведено в таблице 3. В таблице 4 приведено описание управляющих взаимосвязей между объектами.

Таблица 3

Описание элементов объектно-множественной модели процесса составления профессионального глоссария

\begin{tabular}{|c|c|c|c|}
\hline $\begin{array}{l}\text { Основное } \\
\text { множество }\end{array}$ & $\begin{array}{c}\text { Составное } \\
\text { подмножество }\end{array}$ & Описание & $\begin{array}{c}\text { Графическое } \\
\text { представление }\end{array}$ \\
\hline \multirow[b]{2}{*}{$\mathrm{A}_{1}$} & $\mathrm{~A}_{11}$ & $\begin{array}{l}\text { Система загрузки } \\
\text { текста }\end{array}$ & \multirow[b]{2}{*}{$\mathrm{q}_{11,12}$} \\
\hline & $\mathrm{A}_{12}$ & $\begin{array}{l}\text { Система } \\
\text { визуализации } \\
\text { загруженного } \\
\text { текста }\end{array}$ & \\
\hline \multirow{2}{*}{$\mathrm{A}_{2}$} & $\mathrm{~A}_{21}$ & $\begin{array}{l}\text { Система хранения } \\
\text { глоссариев }\end{array}$ & \multirow[b]{2}{*}{$\mathrm{q} 21,22$} \\
\hline & $\mathrm{A}_{22}$ & $\begin{array}{l}\text { Система принятия } \\
\text { решений для } \\
\text { отбора терминов }\end{array}$ & \\
\hline \multirow[b]{2}{*}{$\mathrm{A}_{3}$} & $\mathrm{~A}_{31}$ & $\begin{array}{l}\text { Система } \\
\text { редактирования } \\
\text { глоссария }\end{array}$ & \multirow[b]{2}{*}{$\mathrm{q}_{31,32}\left\lceil\mathrm{q}_{32,31}\right.$} \\
\hline & $\mathrm{A}_{32}$ & $\begin{array}{l}\text { Система } \\
\text { визуализации } \\
\text { готового } \\
\text { глоссария }\end{array}$ & \\
\hline
\end{tabular}


Таблица 4

Описание управляющих взаимосвязей между объектами модели процесса составления профессионального глоссария

\begin{tabular}{|c|c|c|}
\hline Название потока & Вид потока & Описание потока \\
\hline $\mathrm{q}_{11,12}$ & Информационный & $\begin{array}{c}\text { Загрузка текста для } \\
\text { формирования глоссария }\end{array}$ \\
\hline $\mathrm{q}_{21,22}$ & Информационный & $\begin{array}{c}\text { Получение результата анализа } \\
\text { отбора терминов согласно } \\
\text { выдвинутым критериям }\end{array}$ \\
\hline $\mathrm{q}_{31,32}$ & Информационный & $\begin{array}{c}\text { Загрузка полученного глоссария } \\
\text { в хранилище }\end{array}$ \\
\hline $\mathrm{q}_{32,31}$ & Информационный & $\begin{array}{c}\text { Вывод глоссария на } \\
\text { редактирование и ввод } \\
\text { пользовательских данных }\end{array}$ \\
\hline
\end{tabular}

Для основного объекта А определены входы данных $\mathrm{X}=\left\{\mathrm{x}_{1}, \mathrm{x}_{2}, \mathrm{x}_{3}\right\}$ и выходы $\mathrm{Y}=\left\{\mathrm{y}_{2}, \mathrm{y}_{3}\right\}$, где $\mathrm{x}_{1}-$ анализируемый текст, для которого необходимо сформировать глоссарий; $\mathbf{x}_{2}$ - критерии отбора терминов в терминологический глоссарий; х 3 - сформированный системой глоссарий; у2 - отредактированный пользователем глоссарий; уз - готовый глоссарий.

Таким образом, на основе теоретико-множественного анализа модели процесса составления профессионального глоссария в работе выполнено определение основных объектов системы, выявлена их структура и определены все возможные взаимодействия между ними.

МГТУ им. Г.И.Носова в учебной деятельности использует образовательный портал, разработанный на основе LMS Moodle, что является преимуществом для данной работы. Появляется возможность опробовать модель профессионального глоссария и алгоритма для составления профессионального глоссария на практике. 
Рассмотрим возможности LMS Moodle для составления глоссариев подробнее. Глоссарий в системе Moodle - это электронный аналог справочника специальных терминов. Но в отличие от «бумажного» словаря, глоссарий может последовательно создаваться студентами в течение всего периода обучения [14, с. 569]. Узнав новое понятие, студент создает словарную статью, определяет и описывает это понятие, термин [15]. Другие студенты курса могут прокомментировать статью, предложить свои варианты определения. Глоссарий - удобный способ представлять дефиниции, которые будут связаны со всем контентом курса [6, с. 89].

Помимо этого, в LMS Moodle существует два типа глоссариев: главный и вторичный. Вторичные глоссарии являются составной частью главного глоссария (рис. 6).

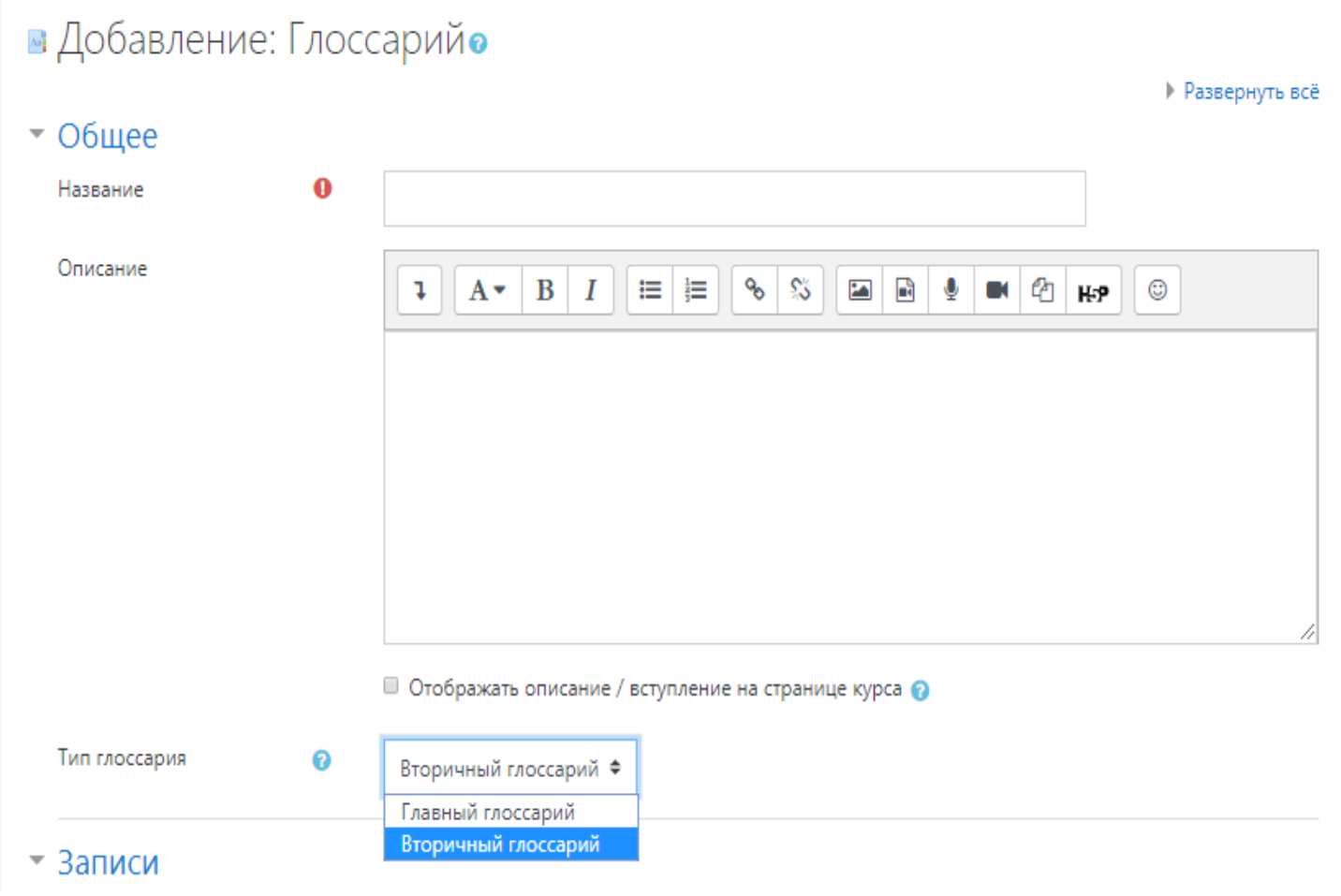

Рис. 6. Вид окна добавления глоссария в LMS Moodle

Также вторичный глоссарий может быть дополнен студентами, в отличие от главного. На курсе может быть только один главный глоссарий и множество вторичных глоссариев. Записи из вторичных глоссариев автоматически 
передаются в главный. Это позволяет строить главный глоссарий, используя вторичные. Студенты не могут изменять записи в главном глоссарии.

Проблема интернационализации терминологической лексики ведущих областей науки и техники становится весьма актуальной. Последнее обусловливается ускоряющимися темпами научно-технической революции, которые приводят к лавинообразному росту информации во всех сферах знаний, производственной и научной деятельности. Это, в свою очередь, влечет за собой появление огромного количества новых понятий и соответственно их наименований, что неизбежно приводит к интенсивному обмену языковыми ценностями, к усилению межъязыковой интерференции. Сложно переоценить важность проверки отобранных терминов (на одном или нескольких языках) экспертами конкретной предметной области до их публикации или использования [17, с. 132]. Глоссарии и терминологические базы - это нормативные документы, которыми, в идеале будут пользоваться как специалисты по коммуникациям внутри организации, так и внешние поставщики коммуникационных услуг (PR, маркетинговые, рекламные и переводческие агентства).

Развитие информационных технологий и совершенствование педагогических подходов позволяет внедрять новые способы усваивания информации студентами высшей школы [18, с. 135]. Также повсеместное внедрение дистанционных технологий образования позволяет создать единое информационное пространство, к которому у студентов есть постоянный доступ.

Современное обучение принимает все более интерактивный характер. Поэтому обучающие информационные пространства требуют все более новые формы взаимодействия преподавателей со студентами [19, c. 8]. Профессиональный глоссарий как раз одна из таких новых форм, которая позволит сформировать компетенции по интеграции английского языка в профессиональной деятельности студентов высшей школы [20, с. 53]. 


\section{Список литературы}

1. Клейман Гленн М. Школы будущего: Компьютеры в процессе обучения. - М.: Радио и связь, - 1987. - 175 с.

2. Дёрина Н.В. Роль глоссариев в лингво-информационной образовательной среде. В сборнике: ab ovo ... (с самого начала...). Сборник Научных трудов. - 2019. - С. 14-17.

3. Якунина Е.К., Дёрина Н.В. Развитие

информационно-технологического потенциала преподавателей университета в процессе корпоративного обучения // Проблемы современного педагогического образования. - 2019. - № 63-1. - С. 428-432.

4. Энциклопедический Словарь Ф.А. Брокгауза и И.А. Ефрона [Электронный ресурс]. Режим доступа: http://www.vehi.net/brokgauz/ (дата обращения 19.10.2021).

5. Асташова Г.В., Дерина Н.В., Савинова Т.А. Обучение пилотов профессиональному языку в процессе иноязычной переподготовки // Вестник Челябинского государственного педагогического университета. - 2018. - № 1. C. $9-18$.

6. Бизнес-Прост. ру [Электронный ресурс]. Режим доступа: https://biznesprost.ru/glossarij.html - (дата обращения 17.10.2021).

7. ГЛОССАРИЙ - Большой энциклопедический словарь [Электронный pecypc]. Режим доступа: https:/gufo.me/dict/bes/ГЛОССАРИЙ - (дата обращения 10.10.2021).

8. Some Aspects and Content of Modern Glossary in Physics [Электронный pecypc]. Режим доступа: http://journale.auris-verlag.de/index.php/EESJ/article/ viewFile/661/657 (дата обращения 21.10.2021).

9. Лешканова Е.О., Бубнова А.С. К вопросу о составлении переводческого глоссария // Филологический аспект. - 2018. - № 4 (36). C. 223-229. 
10. Глоссарий - это... Этимология и происхождение слова. Виды глоссариев [Электронный ресурс]. Режим доступа: http://fb.ru/article/330368/ glossariy---eto-etimologiya-i-proishojdenie-slova-vidyi-glossariev - (дата обращения 20.10.2021).

11. Заруцкая Ж.Н., Ахметзянова Т.Л., Биличенко В.И., Дёрина Н.В., Савинова Т.А. Интерактивные технологии как способ повышения мотивации студентов к изучению иностранного языка // Сборник научных трудов SWorld. 2013. - T. 27. - № 4. - С. 55-58.

12. Davidov V.M., Yakuba T.Yu. Forming glossary of pro-fessional innovatory economic terms for future specialists // Вестник Тихоокеанского государственного университета. - 2007. - № 3 (6). - С.199-208.

13. Рудакова А.Г. Принципы отбора терминологической лексики при составлении словаря терминов по специальности // Горный информационно-аналитический бюллетень (научно-технический журнал). 1999. - №1. - C. 100-101.

14. Gladysheva M., Somova Y., Ilina E., Kalchenko A., Koldin A., Gasanenko E., Dyorina N., Kashchenko T., Yulina G. Results of experimental work at different stages of continuous education for estimation of the formation of research competences of students // Journal of Advanced Research in Dynamical and Control Systems. - 2019. Vol.11. - no. 9 Special Issue. - pp. 569-574.

15. Антропова Л.И., Залавина Т.Ю., Дёрина Н.В. Перевод как вид профессиональной коммуникативной деятельности. Практикум по переводу научно-технических текстов на английском, немецком и французском языках для студентов вузов. Электронное издание / Магнитогорск, - 2019.

16. Плеханова Ю.В. Переводческий глоссарий как эффективный прием подготовки переводчиков // Нижневартовский филологический вестник. - 2016. - № 1. - С. 87-92.

17. Сазонова Е.С., Яковлева И.Н. Составление переводческого глоссария: современные подходы // Подготовка переводчиков в условиях современного 
рынка труда. Колл. монография / под общ. ред. Л.А. Борисовой, Е.А. Княжевой. - Москва: Р. Валент, -2017. - 227 с.

18. Оринина Л.В., Кашуба И.В., Дёрина Н.В., Рабина Е.И. Современные педагогические подходы в системе инженерного образования // Высшее образование в России. - 2019. - Т. 28. - № 6. - С. 129-137.

19. Логунова О.С., Баранкова И.И., Андреев С.М., Чусавитина Г.Н. Институт энергетики и автоматизированных систем: история и перспективы развития направления автоматизированных систем // Математическое и программное обеспечение систем в промышленной и социальной сферах. 2019. - T.7. - № 1. - C. 2-10.

20. Савва Л.И., Дёрина Н.В. Вектор профессионального образования на развитие лидерских качеств в глобализационном мире. Вестник Оренбургского государственного университета. - 2019. - № 2 (220). - С. 49-56.

(C) Н.В. Дёрина, 2021

(C) К.С. Дёрина, 2021 